\title{
Preservation of the Fractured Natural Tooth by Reattachment with Fiber Post: Two Case Reports
}

\author{
${ }^{1}$ SL Satheesh, ${ }^{2}$ Preethi A Koshy, ${ }^{3} \mathrm{C}$ Ganesh, ${ }^{4} \mathrm{M}$ Noora
}

\begin{abstract}
Reattachment of a fractured tooth fragment is a conservative approach that helps to restore form, function, esthetics, and phonetics in a short time. Reattachment procedures have become more predictable with developments in adhesive materials, posts, and preparation techniques that enhance the durability and strength of the procedure. This article discusses the management of two complicated crown fractures that were successfully treated by fragment reattachment using a minimally invasive approach.
\end{abstract}

Keywords: Crown fracture, Fibre post, Reattachment.

How to cite this article: Satheesh SL, Koshy PA, Ganesh C, Noora M. Preservation of the Fractured Natural Tooth by Reattachment with Fiber Post: Two Case Reports. Cons Dent Endod J 2016;1(2):50-54.

Source of support: Nil

Conflict of interest: None

\section{INTRODUCTION}

Fracture of an anterior tooth is one of the most common types of dental injury that require immediate attention. Most commonly affected age groups include children and adolescents. Crown fracture presents 26 to $76 \%$ of all permanent tooth injuries. ${ }^{1}$ A number of classification systems have been proposed to classify traumatic dental injuries. $^{2}$ In 1970, Ellis and Dewey modified Ellis classification and categorized anterior tooth fracture. ${ }^{3,4}$ In 1978, the World Health Organization's (WHO) Application of International Classification of Diseases to Dentistry and Stomatology classified the injuries of oral structures using code numbers considering both primary and permanent dentition. ${ }^{5}$ In 1981, Andreasen modified the WHO classification by including terms uncomplicated (with no pulp involvement)/complicated crown root fracture (with pulp involvement) and concussion/subluxation/ lateral luxation. ${ }^{6}$ Multiple treatment options are available

\footnotetext{
${ }^{1}$ Senior Lecturer, ${ }^{2,4}$ Postgraduate Student, ${ }^{3}$ Professor and Head

${ }^{1-4}$ Department of Conservative Dentistry and Endodontics Sri Sankara Dental College, Thiruvananthapuram, Kerala, India

Corresponding Author: SL Satheesh, Senior Lecturer Department of Conservative Dentistry and Endodontics SriSankara Dental College, Thiruvananthapuram, Kerala, India Phone: +918593044450, e-mail: drsatheeshsl@yahoo.com
}

to restore a fractured tooth, such as composite build-up, veneers or crowns, extraction followed by implant, or fixed partial denture. With the advent of newer dental adhesives and techniques, reattachment of the fractured segment is possible with a minimally invasive approach and can be considered as an excellent alternative to conventional restorations. Reattached fracture segment helps to restore the esthetics by preserving the surface finish, natural translucency of enamel, tooth shape, and color. ${ }^{7}$ This method is very easy to practice and cost effective; further, it helps in achieving functional rehabilitation, as the physiologic wear will be similar to that of natural intact tooth. ${ }^{8}$

The following are the factors that need to be considered before opting for reattachment: ${ }^{7,9}$

- Extent of fracture

- Pulpal and periodontal involvement

- Patient's age

- Dental eruption and root formation

- Adaptation to the remaining tooth

- Extent of dehydration of the fractured segment.

Modifications, such as dentin grooves, bevels, and chamfer given on the tooth or fractured segment remove the fractured enamel prisms, while retaining prisms help in bonding and improve fracture resistance to $97 \%$. ${ }^{9,10}$ Studies have shown that fragment dehydration for more than 1 hour significantly decreases the tooth's fracture resistance as dentin dehydration causes the collapse of collagen fibers which in turn prevents adequate resin infiltration. ${ }^{11}$ It will also affect the esthetics as dehydrated segment will be lighter in color. Therefore, if a fractured segment is dehydrated for more than 1 hour, rehydration of the fractured segment for at least 30 minutes before reattachment will improve the esthetics and bond strength. ${ }^{12}$

\section{CASE REPORTS}

\section{Case 1}

A 21-year-old female patient with a fractured maxillary lateral incisor (\#7), which was caused as a result of fall one day before, was referred to the Department of Endodontics, Sri Sankara Dental College for management.

Clinical examination and radiograph revealed a complicated fracture of maxillary left lateral incisor, and 


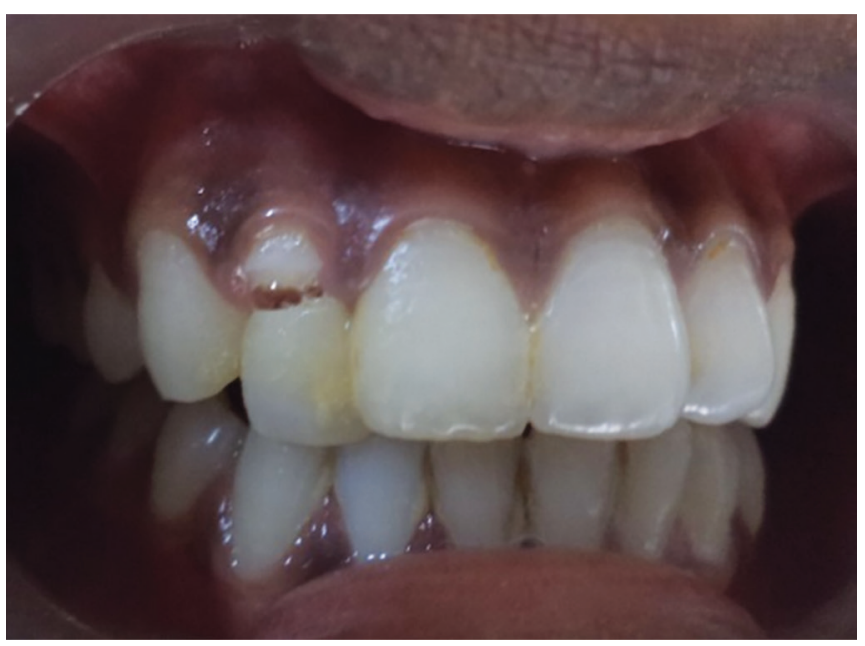

Fig. 1: Fractured maxillary right lateral incisor

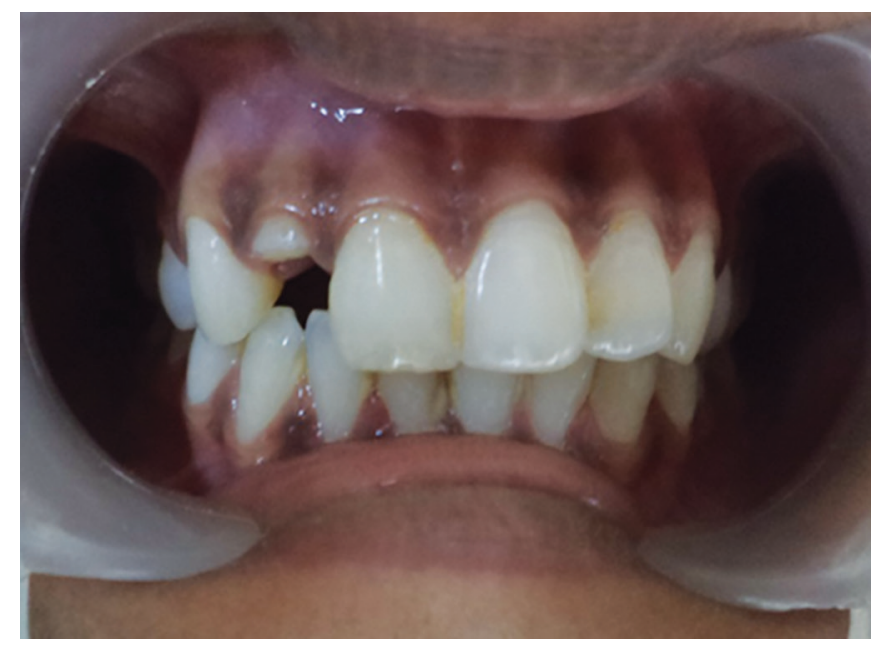

Fig. 3: Labial margin was positioned supragingivally and the lingual margin was present below the marginal gingiva

the fracture line was extending obliquely from the labial to the palatal surface (Figs 1 and 2). The crown margin was supragingival in the labial aspect and extended subgingivally in the palatal aspect. The fractured segment was not completely detached from the crown structure. After administration of local anesthesia (1:200,000 adrenaline, Lignox, Warren Pharmaceuticals Pvt. Ltd., India), the fractured segment was removed (Fig. 2) and kept in distilled water to prevent dehydration and discoloration of the fractured segment (Fig. 3). As the fracture line was below the subgingival level in the palatal aspect, a gingivectomy was performed using No. 15 surgical scalpel. The length of the fractured segment with the remaining tooth was verified.

Working length was determined using electronic apex locator (Root ZX, J Morita, USA) and confirmed using radiograph. Chemo-mechanical preparation was done with stainless steel K-hand files to an apical size of 40 . Sodium hypochlorite (5.25\%, Novo Dental Products Pvt. Ltd., India) and RC help (Prime Dental Products Pvt. Ltd.)

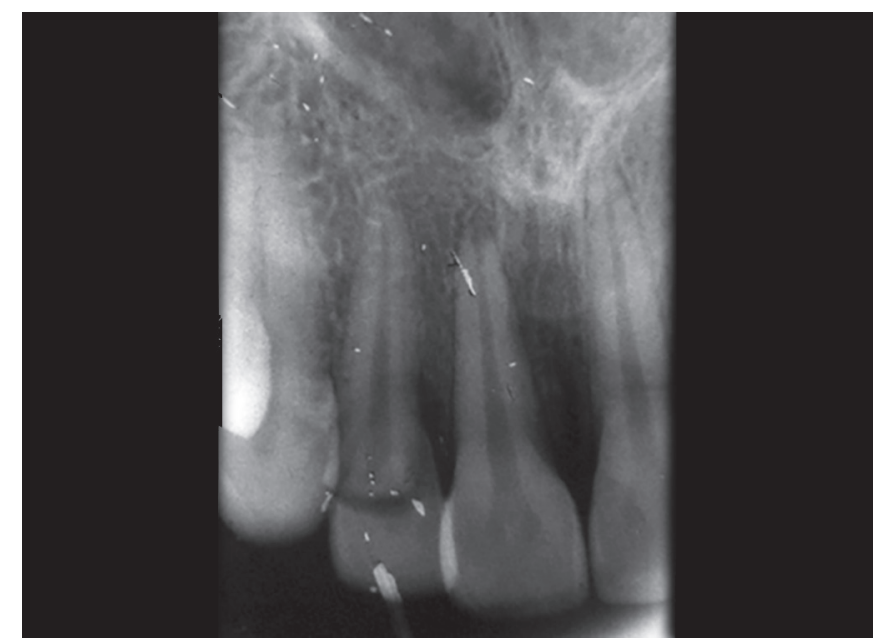

Fig. 2: Preoperative radiograph

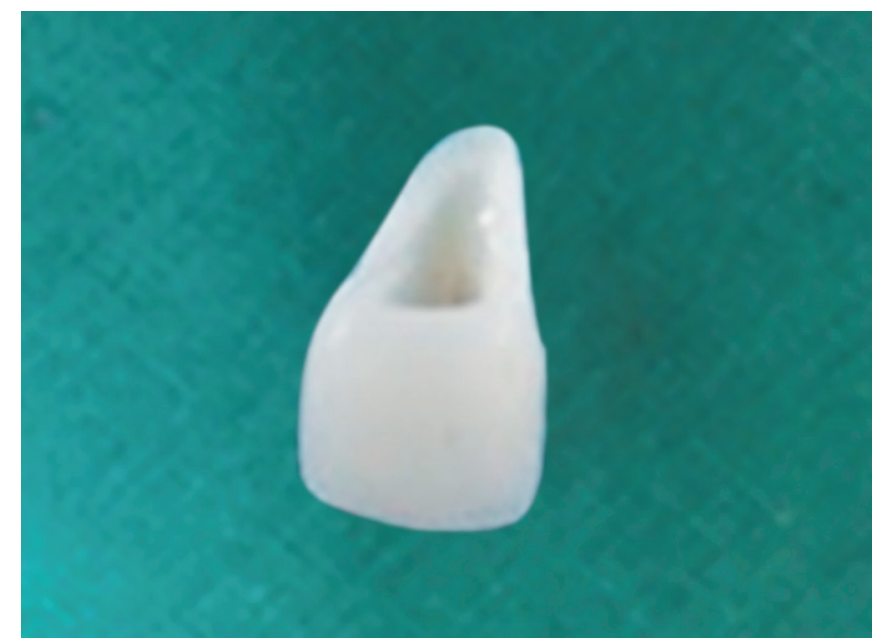

Fig. 4: Fracture fragment

were used alternatively to irrigate the canals during canal preparation. Master cone radiograph was taken to confirm the length of gutta-percha (Dentsply, UK) and the root canal was obturated using lateral condensation technique (Fig. 4) and AH-plus sealer (Dentsply, UK). After the completion of root canal treatment, post space preparation was done using Peeso reamers (size no. 2) leaving apical 4 to $5 \mathrm{~mm}$ of gutta-percha (Figs $5 \mathrm{~A}$ and B). Correspondingly, space was prepared on the fractured segment to contain the coronal portion of the post and core. The fractured tooth and tooth fragment were beveled to improve bonding. Fiber post (Tenax Fiber Trans, Coltene, USA) was placed and adjusted to the desired length and an accurate fit to the coronal fragment was verified. Post space was rinsed and blot dried with paper points. Post was luted in the canal using dual-cured resin luting agent (RelyX ${ }^{\mathrm{TM}}$ Unicem 2 Automix, 3M ESPE, USA) (Fig. 6). The inner portion and bevels of fractured segment were etched with $37 \%$ phosphoric acid, rinsed, and blot dried; further, the bonding agent was applied. 


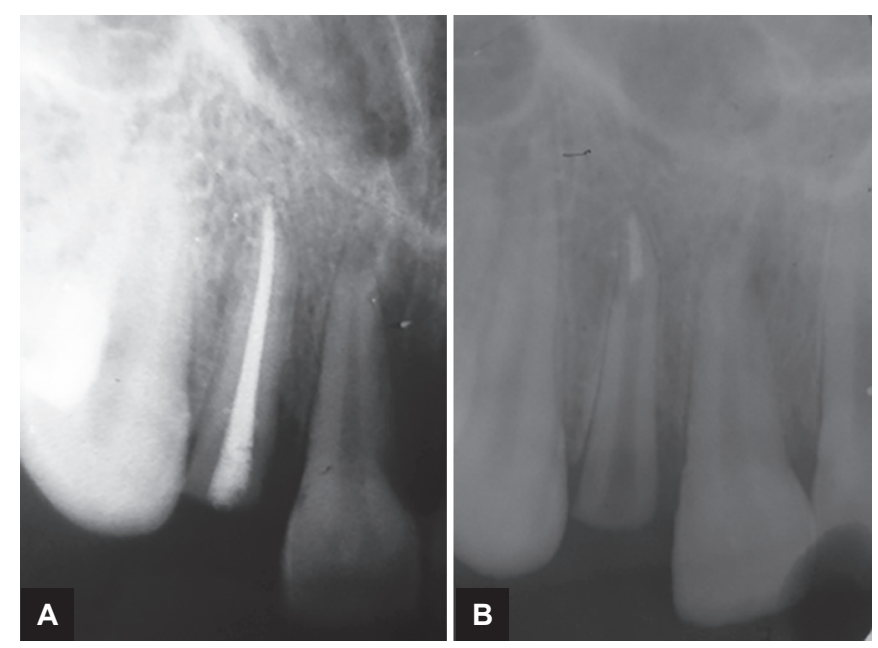

Figs 5A and B: Obturation and post space preparation

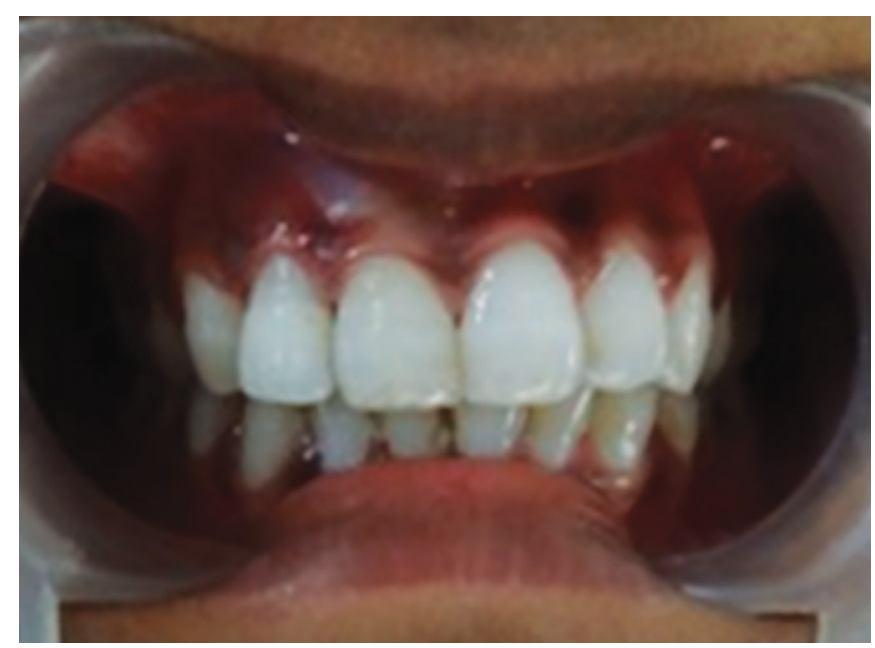

Fig. 7: Postoperative view

After curing flowable composite resin (Filtek ${ }^{\mathrm{TM}}$ Supreme Plus, 3M ESPE, USA), suitable shade was selected and the coronal fragment was bonded to the post. Final finishing and polishing were done with polishing disks (Sof-lex; 3M ESPE, USA) (Fig. 7). Occlusion was checked in centric, lateral, and protrusive excursions. Radiographic examination was done to evaluate the apposition of tooth and fractured segment (Fig. 8).

\section{Case 2}

A 29-year-old male patient with a fractured maxillary left central incisor, which was caused by a road traffic accident the previous year, was referred to the Department of Endodontics, Sri Sankara Dental College for Management.

Clinical examination revealed a complicated fracture of maxillary left central incisor; fracture line was extending obliquely from the labial to the palatal surface with crown margin supragingival labially and subgingival palatally (Figs 9 and 10). The fractured segment was not completely detached from the crown

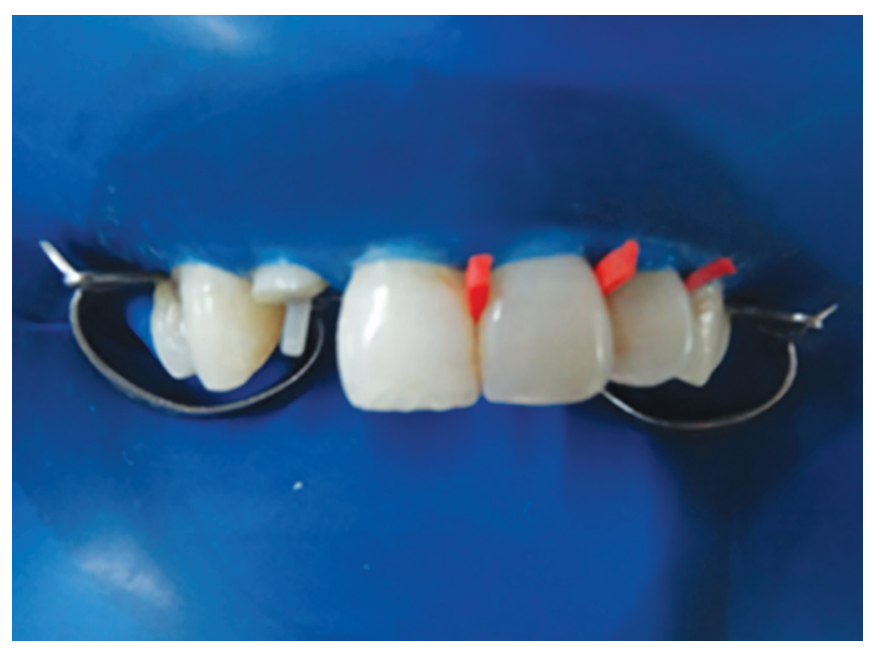

Fig. 6: Fibre post placement

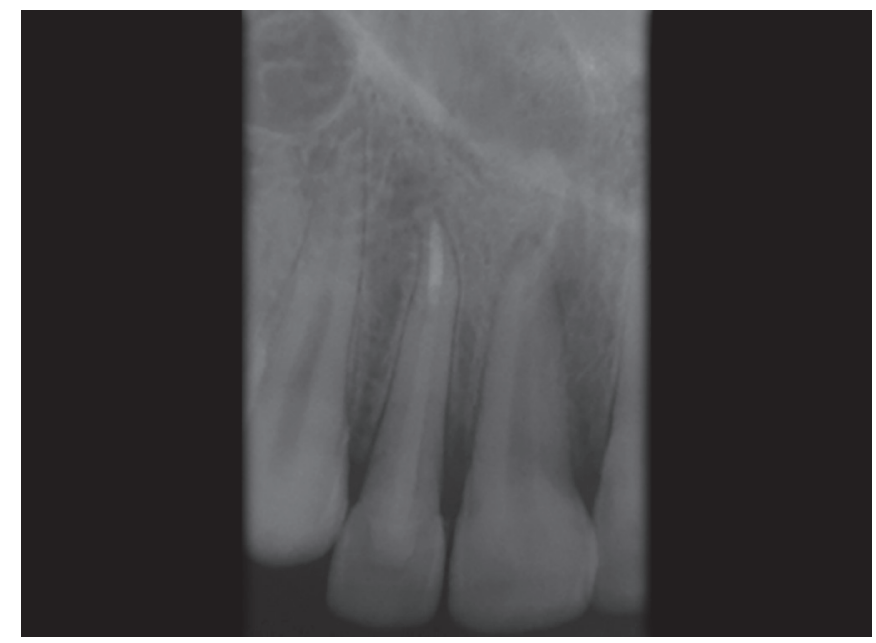

Fig. 8: Postoperative radiograph

structure. Preoperative radiograph was taken to assess the root structure for any fracture or other complications (Fig. 11). After the administration of local anesthesia (1:200,000 adrenaline, Neon Laboratories Ltd, India.), the fractured segment was removed and kept in isotonic saline to prevent dehydration and discoloration of the fractured segment. Gingivectomy was performed using no. 15 surgical scalpel under local anesthesia to expose the fracture line palatally and remove the tissue ingrowth between fractured segments. The length of the fractured segment with the remaining tooth was verified.

Working length was determined using electronic apex locator (Root ZX, J Morita, USA) and confirmed using radiograph. Cleaning and shaping were done with stainless steel K-hand files to an apical size of 55; lubrication was done with $17 \%$ ethylenediaminetetraacetic acid gel. Sodium hypochlorite $(5.25 \%)$ was used for irrigation and normal saline for final irrigation. Master cone radiograph was taken to confirm the length of guttapercha and the root canal was obturated using lateral 


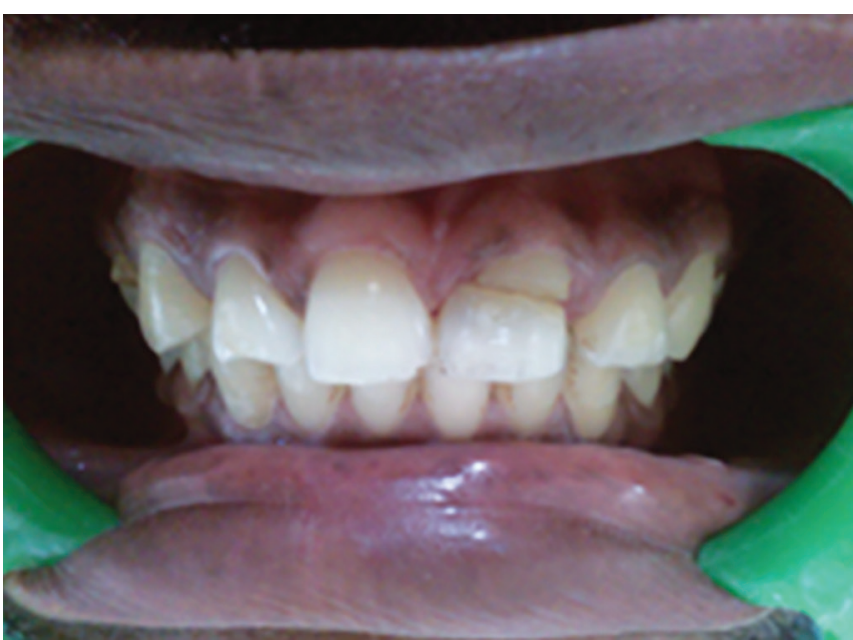

Fig. 9: Preoperative view

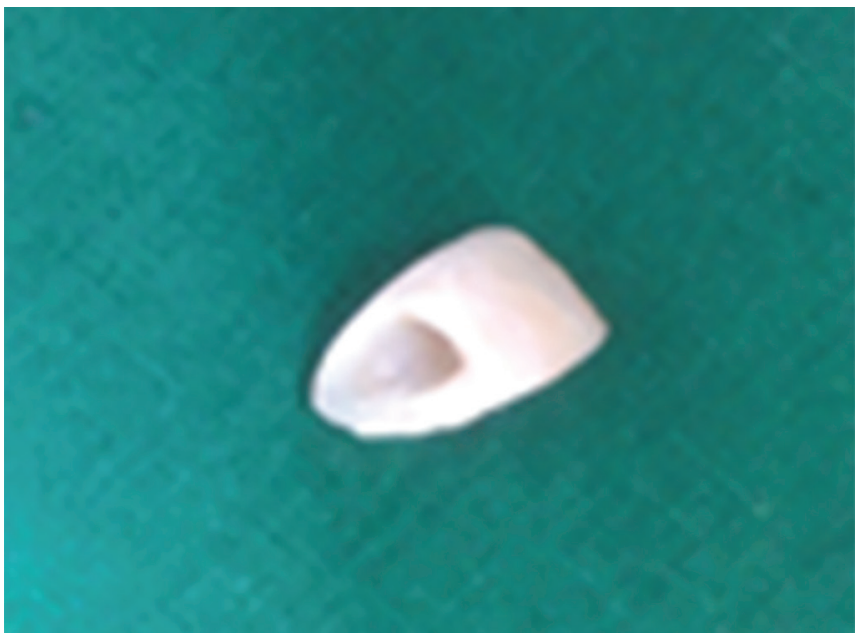

Fig. 11: Fracture fragment

condensation technique and AHPlus resin sealer (Fig. 12A). Post space preparation was done using Peeso reamers (size no. 3) leaving apical $5 \mathrm{~mm}$ of gutta-percha (Fig. 12B). Space was prepared on the fractured segment to contain

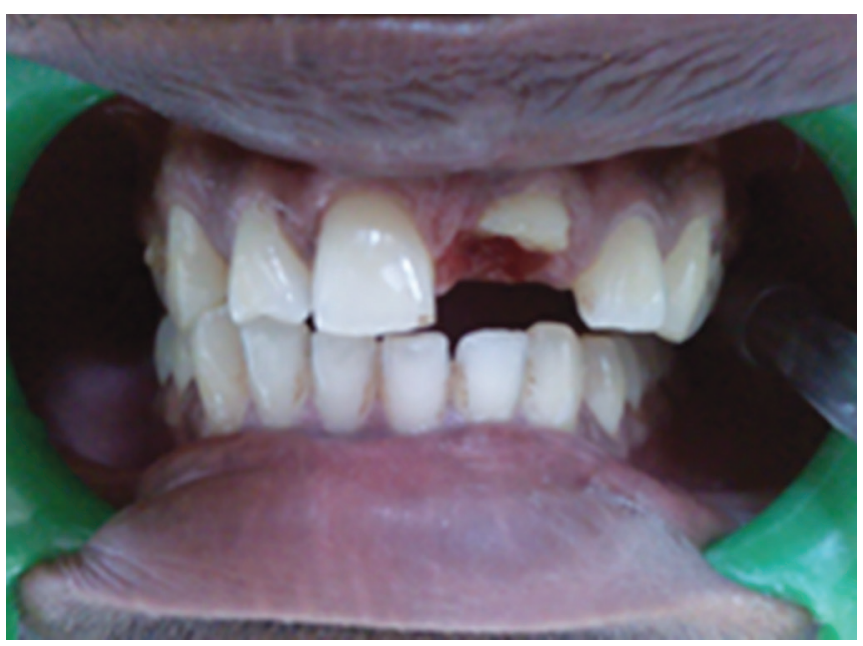

Fig. 10: Fractured maxillary left central incisor

the coronal portion of the post and core with beveling of the tooth margins (Fig. 12C). Fiber post (Tenax Fiber Trans post, Coltene Inc., USA) was placed and adjusted to the desired length and an accurate size to the coronal fragment was verified. Post space and fractured segment were rinsed and blot dried with paper points. Post was luted in the canal using self-adhesive resin luting cement (Rely X U 200, 3M ESPE, USA) followed by bonding of the fractured segment. Final finishing and polishing were done with composite polishing burs (SS White) and disks (Sof-lex; 3M ESPE, USA) (Fig. 12D). Radiographic examination was done to evaluate the length of the fractured segment with the tooth (Fig. 13).

\section{DISCUSSION}

With advances in adhesive dentistry and availability of different types of post and restorative materials, reattachment of fractured tooth is a conservative and cost-effective restorative option for anterior tooth fracture, giving excellent results. Tooth-colored fiber
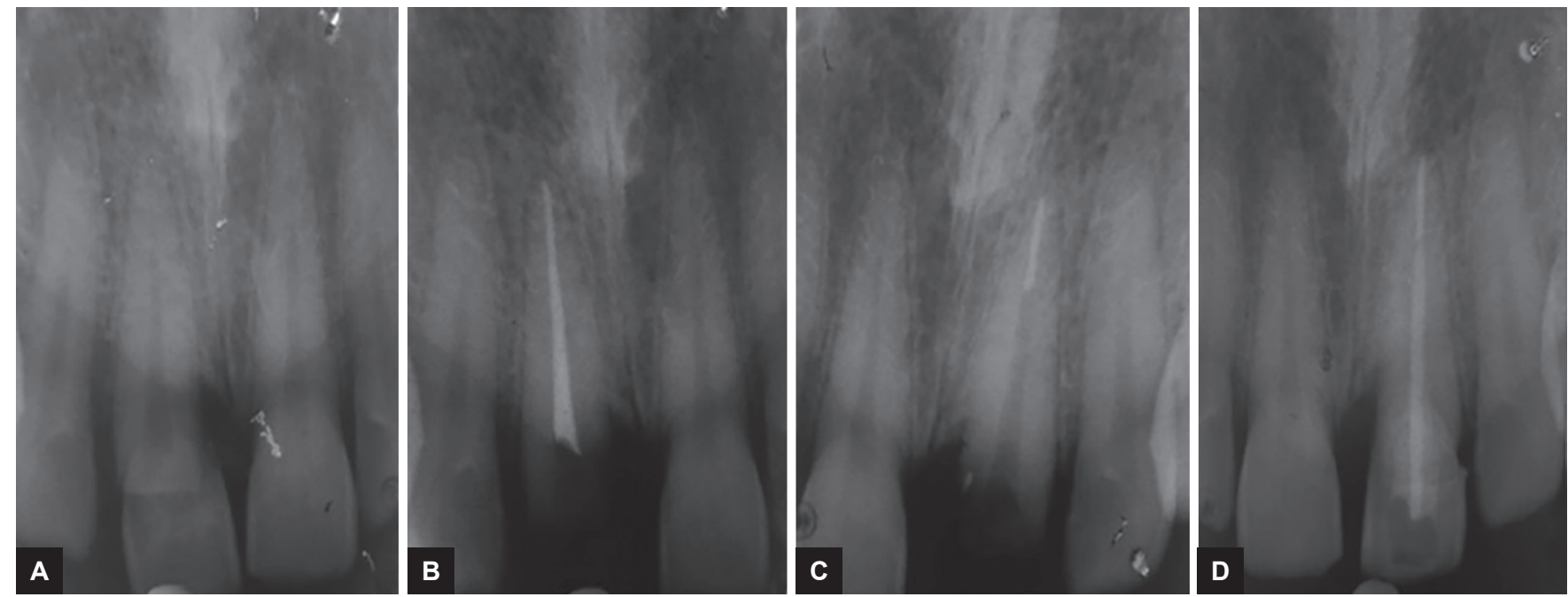

Figs $12 \mathrm{~A}$ to $\mathrm{D}$ : Preoperative radiograph, obturation, post space preparation and postoperative radiograph 


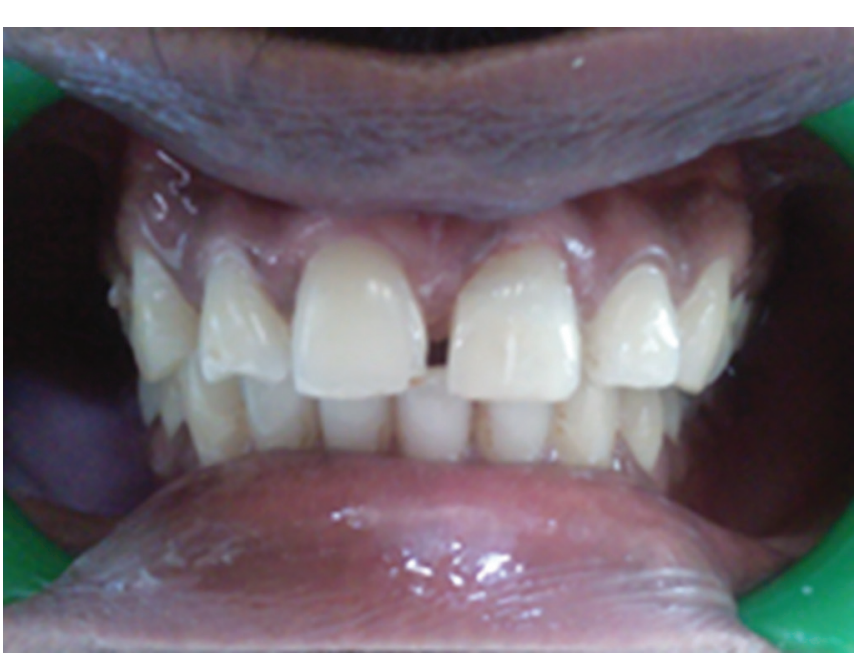

Fig. 13: Postoperative view

posts along with restorative resins provide suitable elastic modulus and uniform distribution of stresses to the radicular dentin. ${ }^{13}$ In this study, we have discussed two case reports of fractured anterior teeth that were successfully reattached using fiber posts. In both cases, the tooth fragments were kept in distilled water before reattachment to prevent dehydration, which can impair esthetics.

However, rehydration of dehydrated crown fragment may occur after reattachment. ${ }^{14}$ The type of luting cement plays an important role in retaining the post. Dual-cure resin cements are a better choice over light cure cements as the degree of conversion is more in the apical regions of post space. In both cases, the post was luted using self-adhesive dual-cured resin cement.

Before reattachment, ensure adequate adaptation of the fracture segment to the crown, as the longevity depends on the proper fit of the coronal fragment. Whenever a proper adaptation of the tooth fragment is not possible or the fracture line is evident, then the addition of resin becomes imperative. ${ }^{15} \mathrm{It}$ is necessary to check the occlusion before and after reattachment to prevent destructive occlusal loading. If the fracture line extends subgingivally invading the biological width, flap surgery with minimal osteoplasty or osteotomy should be done. ${ }^{16,17}$ The possible shortcomings are discoloration or detachment of reattached fragment and bone resorption around subgingival fractures.

\section{CONCLUSION}

Reattachment of tooth fragment is a conservative approach to restore the esthetics, form, and function of the tooth. This minimally invasive approach is very economical and requires less chair time. In case of failure, all the alternative treatment modalities, such as direct resin restoration, veneers, or crowns can be considered.

\section{REFERENCES}

1. Andreasen JO, Ravn JJ. Epidemiology of traumatic dental injuries to primary and permanent teeth in a Danish population sample. Int J Oral Surg 1972;1(5):235-239.

2. Loomba K, Loomba A, Bains R, Bains VK. A proposal for classification of tooth fractures based on treatment need. J Oral Sci 2010 Dec;52(4):517-529.

3. Ellis, RG. The classification and treatment of injuries to the teeth of children. 4th ed. Chicago (IL): Year Book Publisher; 1961. p. 1-229.

4. Pagadala S, Tadikonda DC. An overview of classification of dental trauma. IAIM 2015 Sep;2(9):157-164.

5. World Health Organization. Application of the international classification of diseases to dentistry and stomatology, ICD-DA. 2nd ed. Geneva: WHO; 1978.

6. Andreasen, JO. Traumatic injuries of the teeth. 2nd ed. Copenhagen: Munksgaard; 1981. p. 19-24.

7. Belcheva A. Reattachment of fractured permanent incisors in school children (review). J IMAB - Ann Proc (Scientific Papers) 2008;14(2):96-99.

8. Akyuz SN, Erdemir A. Restoration of tooth fractures using fiber post and fragment reattachment: three case reports. Eur J Gen Dent 2012 May-Aug;1(2):94-98.

9. Lise DP, Vieira LC, Araujo E, Lopes GC. Tooth fragment reattachment: the natural restoration. Oper Dent 2012 NovDec;37(6):584-590.

10. Simonsen RJ. Traumatic fracture restoration: an alternative use of the acid etch technique. Quintessence Int Dent Dig 1979 Feb;10(2):15-22.

11. Farik B, Munksgaard EC, Andreasen JO, Kreiborg S. Drying and rewetting anterior crown fragment prior to bonding. Endod Dent Traumatol 1999 Jun;15(3):113-116.

12. Capp CI, Roda MI, Tamaki R, Castanho GM, Camargo MA, Cara AA. Reattachment of rehydrated dental fragment using two techniques. Dent Traumatol 2009 Feb;25(1):95-99.

13. Torabi K, Fattahi F. Fracture resistance of endodontically treated teeth restored by different FRC posts: an in vitro study. Indian J Dent Res 2009 Jul-Sep;20(3):282-287.

14. Toshihiro K, Rintaro T. Rehydration of crown fragment 1 year after reattachment: a case report. Dent Traumatol 2005 Oct;21(5):297-300.

15. Pagliarini A, Rubini R, Rea M, Campese M. Crown fractures: effectiveness of current enamel-dentin adhesives in reattachment of fractured fragments. Quintessence Int 2000 Feb;31(2):133-136.

16. Baratieri LN, Monteiro Júnior S, Cardoso AC, de Melo Filho JC. Coronal fracture with invasion of the biologic width: a case report. Quintessence Int 1993 Feb;24(2):85-91.

17. Basavanna RS, Kapur R, Sharmaa N. Single visit, reattachment of fractured crown fragment. Contemp Clin Dent 2010 JulSep;1(3):168-170. 